\title{
Endpoint Mobility Ratios for Vertical and Horizontal Wells with Incidence of Scale Deposition
}

\author{
A. Olufemi Bamidele ${ }^{*}, 1$, A.S. Fadairo ${ }^{2}$ and O.A. Falode ${ }^{1}$ \\ ${ }^{I}$ Department of Petroleum Engineering, University of Ibadan, Ibadan, Nigeria \\ ${ }^{2}$ Department of Petroleum Engineering, Covenant University, Otta, Nigeria
}

\begin{abstract}
One of the most difficult and profit hurting problems found in the oil field is the build-up of scale deposits in the well bore, production string, flow lines and even in storage tanks. These deposits act as a restriction during build-up in the wellbore causing a gradual decrease in production and, in many cases, as a solid barrier for wellbore fluid flow.

This paper presents an analytical model based on the existing thermodynamic model showing the endpoint mobility ratios for both vertical and horizontal wells with the incidence of scale precipitation and deposition at the near wellbore region during water flooding.

The results revealed that Endpoint mobility ratio for a vertical well with radial flow approaches unity "1" faster than for the horizontal well with elliptical flow. And horizontal wells are good candidates for managing scale precipitation and deposition during waterflooding.
\end{abstract}

\section{INTRODUCTION}

Scaling phenomenon is a major problem that occurs when water is injected for oil displacement and pressure maintenance in oilfields [1-3]. This phenomenon of precipitation and accumulation of oilfield scale is due to incompartibility between formation and the injected water induced around the wellbore after water breakthrough at reduced reservoir pressure [4,5]. The effects result in formation damage which negatively impact reservoir performance, wellbore performance and the success of waterflooding project that depends on mobility ratio $[6,7]$.

Supplementary recovery results from increasing the natural energy of the reservoir, usually by displacing the hydrocarbons towards the producing wells with some injected fluid. By far the most common fluid injected is water because of its availability, low cost and high specific gravity which facilitates injection.

The basic mechanics of oil displacement by water can be understood by considering the mobilities of the separate fluids. The mobility of any fluid is defined as:

$\lambda=\frac{K K r}{\mu}$

which, considering Darcy's law [8], can be seen to be directly proportional to the velocity of flow. Also included in this expression is the term $\mathrm{kr} / \mu$, which is referred to as the relative mobility.

The favourable type of displacement will only occur if

*Address correspondence to this author at the Department of Petroleum Engineering, University of Ibadan, Ibadan, Nigeria; Tel: +234 803883 5878; E-mails: ofemidele@yahoo.com,ofemidele@gmail.com
$\frac{K_{r w} \mu_{w}}{K_{r o} \mu_{o}}=M \leq 1$

where $\mathrm{M}$ is known as the end point mobility ratio and, since both $\mathrm{K}_{\mathrm{ro}}$ and $\mathrm{K}_{\mathrm{rw}}$ are the end point relative permeabilities, is a constant. If $\mathrm{M} \leq 1$ it means that, under an imposed pressure differential, the oil is capable of travelling with a velocity equal to, or greater than, that of the water. Since it is the water which is pushing the oil, there is therefore, no tendency for the oil to be by-passed which results in the sharp interface between the fluids.

This displacement is called "piston-like displacement". Its most attractive feature is that the total amount of oil that can be recovered from a linear reservoir block will be obtained by the injection of the same volume of water. This is called the movable oil volume where,

$1(M O V)=\left(1-S_{o r}-S_{w c}\right)$

The unfavourable displacement which unfortunately is more common in nature, occurs when $\mathrm{M}>1$. In this case, the water is capable of travelling faster than the oil and, as the water pushes the oil through the reservoir, the latter will be by-passed. Water tongues develop leading to the unfavourable water saturation profile.

Ahead of the water front oil is again flowing in the presence of connate water. This is followed, in many cases, by a waterflood front, or shock front, in which there is a discontinuity in the water saturation. There is then a gradual transition between the shock front saturation and the maximum saturation,

$S_{w}=1-S_{o r}$

At a constant rate of water injection, the fact that much more water must be injected, in the unfavourable case, 
protracts the time scale attached to the oil recovery and this is economically unfavourable. In addition, pockets of bypassed oil are created which may never be recovered.

\section{MODEL DEVELOPMENT}

Assuming an idealised flow, Fadairo and Omole [6,7] expressed the effect of scale build up on permeability variation, skin factor and additional pressure drop across the skin based on exponential shape for both porosity and permeability damage function as;

$$
K_{s}=K_{i}\left(1-F\left[\frac{d C}{d P}\right]_{T}\right)^{3.0}
$$

where $\mathrm{K}_{\mathrm{s}}$ is defined as the instantaneous permeability as a result of solid scale saturation near a vertical wellbore region with exponent of " 3 " [2,9].

The effect of oil field scale build up on the skin factor at different pore volume of sea water injected can be expressed as;

$$
S_{\text {vertical }}=\left[\frac{K}{K_{0}}\left[\left(1-F \frac{d C}{d P}\right)^{-3.0}-1\right]\right] \ln r_{s} / r_{w}
$$

Endpoint Mobility ratio for a radial flow of water with the incidence of scale deposition around a vertical wellbore can therefore be expressed as:

$$
M=\frac{1}{q_{o} \operatorname{Ln} \frac{r_{\text {oil }}}{r_{\text {well }}}}\left(\frac{141.2 K K_{r w} \Delta P_{T}}{\mu}+q_{w}\left[\operatorname{Ln} \frac{r_{\text {water }}}{r_{\text {well }}}+s\right]\right)
$$

While Endpoint Mobility ratio for an elliptical flow of water with the incidence of scale deposition around a horizontal wellbore can be expressed as:

$$
M=\frac{\frac{141.2 \Delta P_{T} h K K_{r w}}{\mu_{w}}+q_{w} B_{w}\left[\ln \left[\frac{a+\sqrt{a^{2}+(L / 2)^{2}}}{L / 2}\right]+\ln \left(\frac{h}{2 r_{w}}\right)+s_{\text {horizontal }}\right]}{q_{o} B_{o} \ln \left[\frac{a+\sqrt{a^{2}+(L / 2)^{2}}}{L / 2}+\ln \left(\frac{h}{2 r_{w}}\right)\right]}
$$

The details of the derivation can be seen in the Appendix $\mathbf{A}$ and $\mathbf{B}$.

\section{RESULTS AND DISCUSSION}

Horizontal Well Length: Fig. (1) revealed that as the horizontal well length increases, mobility ratio also increases, and, beyond $1300 \mathrm{ft}$ it becomes unfavourable and greater than unity resulting in premature breakthough of water.

Pore Water Injected: As the water injected increases, mobility ratio increases and faster to approach the value of unity " 1 " (for a stable and pistonlike displacement to occur) for $1500 \mathrm{ft}$ horizontal well length. However, it least approach unity for a $100 \mathrm{ft}$ reservoir (Fig. 2).

Skin Factor: It is shown in Fig. (3) that mobility ratio increases with increasing formation damage. As the horizontal well length increases from 100 feet (ft) to 600 feet (ft), mobility ratio is greater than unity and becomes much more unfavourable for reservoir thickness of $60 \mathrm{ft}$.

Mobility Ratio of Radial and Elliptical Flow: Endpoint mobility ratio for a vertical well radial flow approaches unity "1" faster than for the horizontal well elliptical flow. This results in the by-passing of oil and consequently the premature breakthrough of water (Fig. 4).

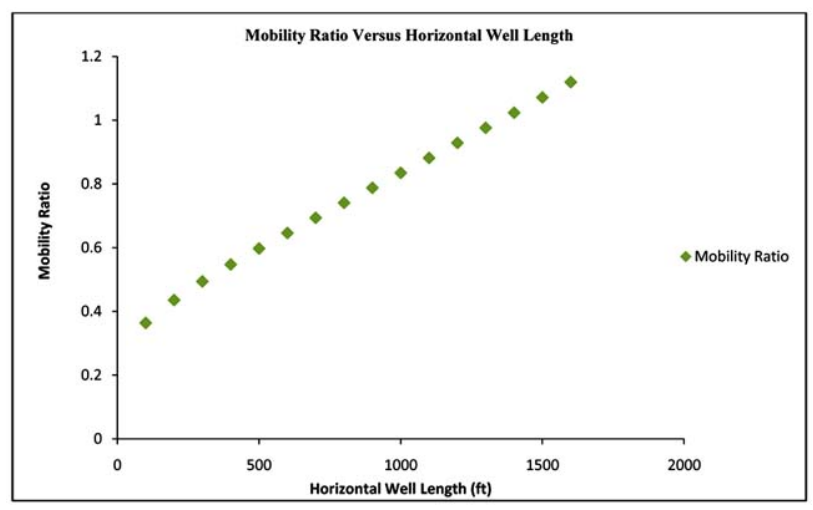

Fig. (1). Endpoint mobility ratio versus horizontal well length, $\mathrm{h}=20 \mathrm{ft}$.

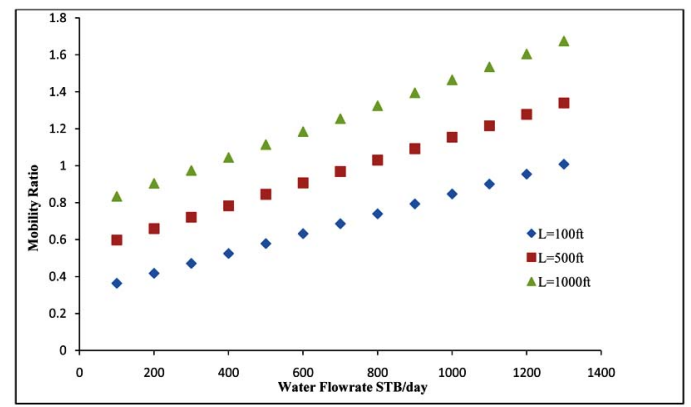

Fig. (2). Endpoint mobility ratio versus water flow rate at varied horizontal well length. 


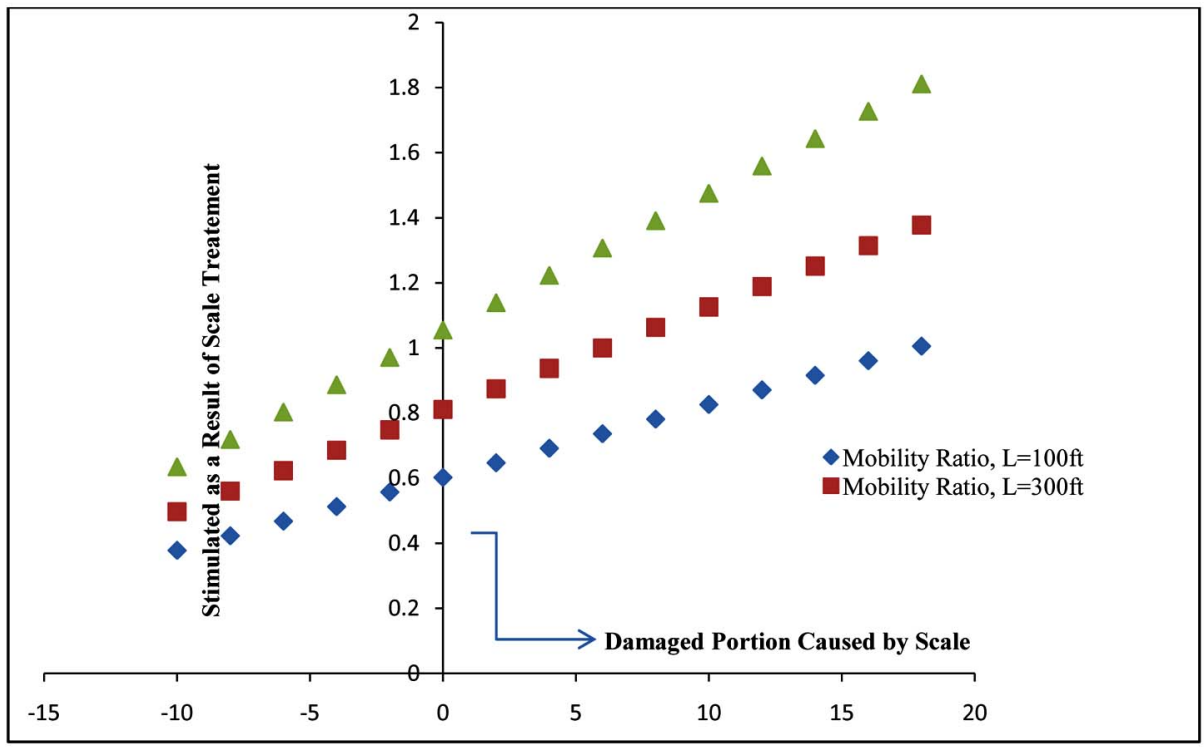

Fig. (3). Mobility ratio and skin factor, $h=60$ ' for horizontal well with elliptical flow.

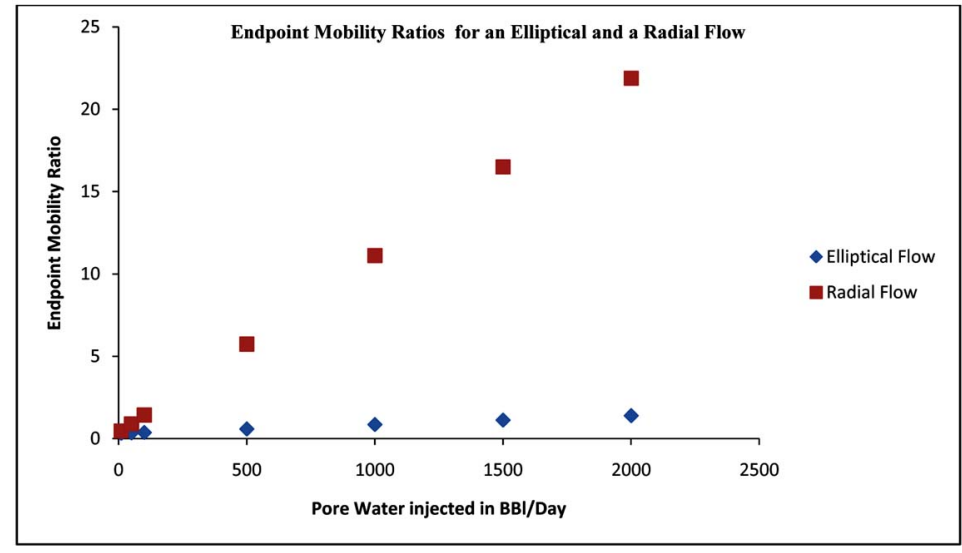

Fig. (4). Endpoint mobility ratios of a vertical radial flow and horizontal elliptical flow.

\section{CONCLUSION}

The following conclusions were drawn from the results of this study:

Table 1. Fluid and Reservoir Parameters used as Input in the Scale Prediction Models [2,5,10,11]

\begin{tabular}{|c|c|}
\hline $\mathrm{a}$ & $1114 \mathrm{ft}$ \\
\hline $\mathrm{L}$ & Varies \\
\hline $\mathrm{r}_{\mathrm{w}}$ & $0.365 \mathrm{ft}$ \\
\hline $\mathrm{h}$ & Varies \\
\hline $\mathrm{B}_{\mathrm{w}}$ & $1.02 \mathrm{bbl} / \mathrm{D}$ \\
\hline$\mu_{\mathrm{o}}$ & $1.6 \mathrm{cp}$ \\
\hline$\mu_{\mathrm{w}}$ & $1 \mathrm{cp}$ \\
\hline $\mathrm{Krw}$ & $0.04 \mathrm{mD}$ \\
\hline $\mathrm{Kro}$ & $2.5 \mathrm{mD}$ \\
\hline$\Delta \mathrm{P}$ & Varies \\
\hline$\left[\frac{d C}{d P}\right]_{85^{\circ} C}$ & $5.0 \mathrm{E}-15 \mathrm{mg} / \mathrm{m}^{3}-\mathrm{pa}$ \\
\hline
\end{tabular}

Endpoint mobility ratio of both vertical and horizontal wells due to sulphate scale deposition is the function of operational and reservoir/brine parameters such as scale concentration in the brine, viscosity of brine, formation volume factor of the brine, solid scale density, injection rate, pressure drawdown, reservoir temperature, reservoir thickness and brine velocity.

Mobility ratio increases with increasing formation damage.

Thick reservoir approaches unfavourable mobility ratio faster than thin oil reservoirs with incidence of scale deposition.

Endpoint mobility ratio for a vertical well radial flow approaches unity " 1 " faster than for the horizontal well elliptical flow.

\section{APPENDIX A}

\section{Model Development}

Pressure gradient due to the presence of scale in the flow path as follows $[3,4]$. 


$$
\frac{d P}{d r}=\frac{q \mu B e^{\left(3 k_{d e p} C t\right)}}{2 \pi k h r_{s}}
$$

In which $\xi_{\phi}=e^{3 k_{d e p} C . t}$ and $\Psi_{\phi}=3 k_{d e p} C$ is defined as formation damage coefficient. From this equation, the formation damage coefficient is a function of time.

Instantaneous local porosity is defined as the difference between the initial porosity and the damaged fraction of the pore spaces i.e. the fraction of the mineral scale that occupied the total volume of the porous media.

That is,

$\phi_{s}=\phi_{0}-\phi_{m}$

$\frac{\phi_{s}}{\phi_{0}}=1-\frac{\phi_{m}}{\phi_{0}}$

$\phi_{s}=\phi_{0}-\frac{\text { volume }_{\text {scale }}}{\text { volume }_{\text {pores }}}$

The volume of scale $d V$ which drops out and get deposited in the volume element over the time interval, $d t$, is given as follows: [2]

$d V=q\left[\frac{d C}{\rho d P}\right]_{T} d P . d t$

where $\left(\frac{d C}{d P}\right)_{T}$ is defined as the change in saturated solid scale content per unit change in pressure at constant temperature.

Hence, the change in porosity due to scale deposition over time interval is given as:

$$
\begin{aligned}
d \phi_{m} & =\frac{q\left[\frac{d C}{d P}\right]_{T} \frac{q \mu B e^{\left(3 k_{d e p} C t\right)}}{2 \pi k h r_{s}} \cdot d r . d t}{2 \pi r_{s} d r h \rho} \\
d \phi_{m} & =\frac{q^{2}\left[\frac{d C}{d P}\right]_{T} \mu B e^{\left(3 k_{d e p} C t\right)} d t}{4 \pi^{2} r_{s}^{2} h^{2} \rho}
\end{aligned}
$$

Integrating equation (A-5)

$$
\phi_{m}=\frac{q^{2}\left[\frac{d C}{d P}\right]_{T} \mu B e^{\left(3 k_{d e p} C . t\right)}}{4 \pi^{2} r_{s}^{2} h^{2} \rho .3 k_{d e p} C}
$$

where $\psi_{\phi}=3 k_{d e p} C$ and $e^{3 k_{d e p} C t}=\xi_{\phi}$

$$
\phi_{m}=\frac{q^{2}\left[\frac{d C}{d P}\right]_{T} \mu B \xi_{k}}{4 \pi^{2} r_{s}^{2} h^{2} \rho \cdot 3 k_{d e p} C}
$$

$\phi_{m}=\frac{q^{2}\left[\frac{d C}{d P}\right]_{T} \mu B \xi_{\phi}}{4 \pi^{2} r_{s}^{2} h^{2} \rho \cdot \Psi_{\phi}}$

By substituting (A-7) into (A-2)

$$
\frac{\phi_{m}}{\phi_{o}}=\frac{q^{2}\left[\frac{d C}{d P}\right]_{T} \mu B \xi_{\phi}}{4 \pi^{2} r_{s}^{2} h^{2} \phi_{o} \rho \cdot \Psi_{\phi}}
$$

where $\frac{\phi_{m}}{\phi_{o}}$, which is the pore volume occupied by scale.

Expressing this volume as a fraction of the total pore volume occupied by oil, we then have:

$\frac{\phi_{s}}{\phi_{o}}=1-\frac{\phi_{m}}{\phi_{0}}=1-\frac{q^{2}\left[\frac{d C}{d P}\right]_{T} \mu B \xi_{\phi}}{4 \pi^{2} r_{s}^{2} h^{2} \phi_{o} \rho \cdot \Psi_{\phi}\left(1-S_{w c}\right)}$

Let $F=\frac{q^{2} \mu B \xi_{\phi}}{4 \pi^{2} r_{s}^{2} h^{2} \phi_{o} \rho . \Psi_{\phi}\left(1-S_{w c}\right)}$

$\frac{\phi_{s}}{\phi_{o}}=1-F\left[\frac{d C}{d P}\right]_{T}$

where, $\frac{d C}{d P}$ is determined by the thermodynamic model of each salt involved [12].

By expressing the initial and instantaneous permeabilities as a function of altered porosity $[2,9]$ we have:

$\frac{K_{s}}{K_{o}}=\left(\frac{\phi}{\phi_{0}}\right)^{3.0}$

$K_{s}=K_{0}\left[\frac{\phi}{\phi_{0}}\right]^{3.0}$

By substituting the skin formula we have

$K_{s}=K_{o}\left[1-F\left[\frac{d C}{d P}\right]\right]^{3.0}$

And simply, skin factor can be expressed as

$s_{\text {vertical }}=\left(\frac{K}{K_{s}}-1\right) \ln r_{s} / r_{w}$

We can express the relationship between horizontal and vertical well damage as [13]:

$$
\begin{aligned}
& s_{\text {horizontal }}=(\beta h / L) s_{\text {vertical }} \\
& s_{\text {horizontal }}=\left(\beta h / L\left[\left(k / k_{s}\right)-1\right] \ln \left(r_{s} / r_{w}\right)\right)
\end{aligned}
$$

Substituting (A-9) into (A-10), we have: 
$S_{\text {vertical }}=\left[\frac{K}{K_{0}}\left[\left(1-F \frac{d C}{d P}\right)^{-3.0}-1\right]\right] \ln r_{s} / r_{w}$

We also have for the horizontal skin factor due to scale as:

$$
s_{\text {horizontal }}=\frac{\beta h}{L}\left[\frac{K}{K_{0}}\left[\left(1-F \frac{d C}{d P}\right)^{-3.0}-1\right]\right] \ln r_{s} / r_{w}
$$

At the initial start of production, when time is zero, $q=0$, and since $\mathrm{F}$ depends on $\mathrm{q}, \mathrm{F}$ is also equal to zero, and the initial permeability is equal to the intantaneous permeability i.e $K=K_{o}$ and there will be no skin due to scale, i.e shorizontal $=0$,

By subtituting (A-11) into horizontal fluid flow equation $[10,11]$, we then have:

$$
q_{h}=\left[\frac{141.2 h \Delta p}{B}\right] \frac{K}{\mu} /\left\{\begin{array}{l}
\ln \left[\frac{a+\sqrt{a^{2}-(L / 2)^{2}}}{L / 2}\right] \\
+h / L \ln \left(\frac{h}{2 r_{w}}\right)+s_{\text {horizontal }}
\end{array}\right\}
$$

And for productivity index:

$$
J_{h}=\frac{q_{h}}{\Delta p}=\left[\frac{141.2 k h}{\mu \beta}\right] /\left\{\begin{array}{l}
\ln \left[\frac{a+\sqrt{a^{2}-(L / 2)^{2}}}{L / 2}\right] \\
+\beta h / L \ln \left(\frac{h}{2 r_{w}}\right) \\
+\frac{\beta h}{L}\left[\frac{k_{H}}{k_{0}}\left[\left(1-F \frac{d C}{d P}\right)^{-3.0}-1\right]\right] \ln r_{s} / r_{w}
\end{array}\right\}
$$

For $L \succ h$ and $(L / 2) \prec 0.9 r_{e H}$

where, $\mathrm{J}_{\mathrm{h}}$ is the horizontal well productivity index.

If $\mathrm{k}_{\mathrm{v}}=\mathrm{k}_{\mathrm{h}}, \beta=1$, which implies that, vertical permeability is equal to the horizontal permeability.

And, "a" is the half of the major axis of a drainage ellipse in a horizontal plane in which the well is located and can be reformulated as:

$a=\frac{L}{2}\left[\frac{1}{2}+\sqrt{1 / 4+\frac{1}{\left(0.5 L / r_{e H}\right)^{4}}}\right]^{0.5}$ and

$\ln \left[\frac{a^{2}+\sqrt{a^{2}-(L / 2)^{2}}}{L / 2}\right]+h / L \ln \left(\frac{h}{2 r_{w}}\right)$ is a dimentional

factor that converts the conventional Darcy [8] equation of fluid flow in porous media for a vertical well into a horizontal well fluid flow pattern.

$$
q_{h}=\left[\frac{141.2 h \Delta p_{o}}{\beta}\right] \frac{K_{o}}{\mu_{o}} /\left\{\ln \left[\frac{a+\sqrt{a^{2}-(L / 2)^{2}}}{L / 2}\right]+h / L \ln \left(\frac{h}{2 r_{w}}\right)\right\}
$$

Assuming that the vertical injection well is located around the producing horizontal well and the flow around the horizontal well is elliptical. The total pressure drop as a result of water pushing oil can be expressed as:

$\Delta P_{t}=\Delta P_{o}+\Delta P_{w}+\Delta P_{g}+\Delta P_{\text {scale }}$

For Oil Phase:

$\Delta P_{o}=\frac{q_{o} \mu_{o} B_{o}[A]}{0.00708 K K_{r o} h}$,

For Water Phase:

$\Delta P_{w}=\frac{q_{w} \mu_{w} B_{w}[A]}{0.00708 K K_{r w} h}$,

For Gas Phase:

$\Delta P_{g}=\frac{q_{g} \mu_{g} B_{g}[A]}{0.00708 K K_{r g} h}$, and,

For Scale:

$\Delta P_{\text {scale }}=\frac{q_{w} \mu_{w} B_{w}}{0.00708 K K_{r w} h} s_{\text {horizontal }}$,

Let,

$[A]=\left\{\ln \left[\frac{a+\sqrt{a^{2}-(L / 2)^{2}}}{L / 2}\right]+h / L \ln \left(\frac{h}{2 r_{w}}\right)\right\}$

and,

$S_{\text {horizontal }}=\frac{\beta h}{L}\left[\frac{K}{K_{0}}\left[\left(1-F \frac{d C}{d P}\right)^{-3.0}-1\right]\right] \ln r_{s} / r_{w}$

Since gas does not carry any particle and assumed to be a non-wetting phase, therefore, $\Delta P_{g} \approx 0$. Then equation (12) becomes:

$$
\begin{aligned}
\Delta P_{T}= & -\frac{q_{o} \mu_{o} B_{o}[A]}{0.00708 K K_{r o} h}-\frac{q_{w} \mu_{w} B_{w}[A]}{0.00708 K K_{r w} h} \\
& -\frac{q_{w} \mu_{w} B_{w}}{0.00708 K K_{r w} h} S_{\text {horizontal }} \\
\Delta P_{T}= & -\frac{q_{o} \mu_{o} B_{o}[A]}{0.00708 K K_{r o} h} \\
& -\frac{q_{w} \mu_{w} B_{w}}{0.00708 K K_{r w} h}\left[A+s_{\text {horizontal }}\right]
\end{aligned}
$$


$\Delta P_{T}=\frac{141.2}{h}\left[\frac{q_{o} \mu_{o} B_{o}[A]}{K K_{r o}}-\frac{q_{w} \mu_{w} B_{w}}{K K_{r w}}\left[A+s_{\text {horizontal }}\right]\right]$ By

dividing the equation by $\frac{\mu_{w}}{K K_{r w}}$

$\frac{141.2 \Delta P_{T} h K K_{r w}}{\mu_{w}}=\frac{K K_{r w} \mu_{o} q_{o} B_{o}}{K K_{r o} \mu_{w}}[A]-q_{w} B_{w}\left[A+s_{\text {horizontal }}\right]$

$\frac{141.2 \Delta P_{T} h K K_{r w}}{\mu_{w}}=q_{o} B_{o}[A]-q_{w} B_{w}\left[A+s_{\text {horizontal }}\right]$

$M q_{o} B_{o}[A]=\frac{141.2 \Delta P_{T} h K K_{r w}}{\mu_{w}}+q_{w} B_{w}\left[A+s_{\text {horizontal }}\right]$

$M=\frac{\frac{141.2 \Delta P_{T} h K K_{r w}}{\mu_{w}}+q_{w} B_{w}\left[A+s_{\text {horizontal }}\right]}{q_{o} B_{o}[A]}$

$M=\frac{\frac{141.2 \Delta P_{T} h K K_{n w}}{\mu_{w}}+q_{w} B_{w}\left[\ln \left[\frac{a+\sqrt{a^{2}+(L / 2)^{2}}}{L / 2}\right]+\ln \left(\frac{h}{2 r_{w}}\right)+S_{\text {horizonal }}\right]}{q_{o} B_{o} \ln \left[\frac{a+\sqrt{a^{2}+(L / 2)^{2}}}{L / 2}+\ln \left(\frac{h}{2 r_{w}}\right)\right]}$

where,

$$
S_{\text {horizontal }}=\frac{\beta h}{L}\left[\frac{K}{K_{0}}\left[\left[1-F \frac{d C}{d P}\right]^{-3.0}-1\right]\right] \ln r_{s} / r_{w}
$$

\section{APPENDIX B}

Consider the simultaneous radial flow of oil and injected water, saturated with solid mineral scale particle at location $\mathrm{r}$, from a vertical wellbore. The total pressure drop across the vertical wellbore is the summation of the pressure drop due to flow of oil and water. That is:

$\Delta P_{T}=\Delta P_{w}+\Delta P_{o}+\Delta P_{s}$

$\Delta P_{T}=\frac{q_{w} \mu_{w}}{2 \pi K K_{\text {ro }}} \operatorname{Ln} \frac{r_{\text {water }}}{r_{\text {well }}}-\frac{q_{o} \mu_{o}}{2 \pi K K_{w}}\left\{\left[1-F\left(\frac{d C}{d P}\right)_{T}-1\right]^{-3.0}\right\} \operatorname{Ln} \frac{r_{s}}{r_{w}}$

By rearranging this we have;

$$
\begin{aligned}
\Delta P_{T}= & \frac{q_{w} \mu_{w}}{2 \pi h K K_{r w}}\left[\operatorname{Ln} \frac{r_{\text {water }}}{r_{\text {well }}}+\left\{\left[1-F\left(\frac{d C}{d P}\right)_{T}\right]^{-3.0}\right\} \operatorname{Ln} \frac{r_{s}}{r_{\text {well }}}\right] \\
& -\frac{q_{o} \mu_{o}}{2 \pi h K K_{r o}} \operatorname{Ln} \frac{r_{\text {oil }}}{r_{\text {well }}}
\end{aligned}
$$$$
\frac{2 \pi h K K_{r w} \Delta P_{T}}{\mu_{w}}=-q_{w}\left[\operatorname{Ln} \frac{r_{\text {water }}}{r_{\text {well }}}+\left\{\left[1-F\left(\frac{d C}{d P}\right)_{T}\right]^{-3.0}\right\} \operatorname{Ln} \frac{r_{s}}{r_{\text {well }}}\right]-q_{o} M L n \frac{r_{\text {oil }}}{r_{\text {well }}}
$$

$\frac{2 \pi h K K_{r w}}{q_{o} \mu_{w} L n \frac{r_{\text {oil }}}{r_{\text {well }}}}+\frac{q_{w}}{q_{o} L n \frac{r_{\text {oil }}}{r_{\text {well }}}}\left[\operatorname{Ln} \frac{r_{\text {water }}}{r_{\text {well }}}+\left\{\left[1-F\left(\frac{d C}{d P}\right)_{T}\right]^{-3.0}\right\} \operatorname{Ln} \frac{r_{s}}{r_{\text {well }}}\right]=M$

$$
M=\frac{1}{q_{o} \operatorname{Ln} \frac{r_{\text {oil }}}{r_{\text {well }}}}\left(\frac{141.2 h K K_{r w} \Delta P_{T}}{\mu_{w}}+q_{w}\left[\operatorname{Ln} \frac{r_{\text {water }}}{r_{\text {well }}}+s\right]\right)
$$

where $\mathrm{s}$ is the skin factor, which can be expressed as:

$$
s_{\text {vertical }}=\left[\frac{K}{K_{0}}\left[\left(1-F \frac{d C}{d P}\right)^{-3.0}-1\right]\right] \ln r_{s} / r_{w}
$$

\section{Symbols Used}

$$
\begin{aligned}
& \mathrm{C}=\text { Salt Concentration } \\
& \mathrm{V}=\text { Volume of scale } \\
& q \quad=\text { Flow rate bbl/day } \\
& \rho \quad=\text { Density } \\
& \mathrm{t}=\text { Production time, hours (hrs) } \\
& \mathrm{T}=\text { Temperature, Degree Celcius }\left({ }^{\circ} \mathrm{C}\right) \\
& r \quad=\text { Radius feet }(\mathrm{ft}) \\
& \phi_{m} \quad=\text { Damaged fraction porosity, (\%) } \\
& K=\text { Permeability milli-Darcy }(\mathrm{mD}) \\
& \mathrm{h} \quad=\text { ReservoirThickness, feet }(\mathrm{ft}) \\
& \mathrm{P} \quad=\text { Pressure } \mathrm{lb} / \mathrm{in}^{2}(\mathrm{psi}) \\
& \mathrm{B}=\text { Formation Volume Factor rb/STB } \\
& K_{\text {dep }} \quad=\text { Deposition rate constant } \\
& \Psi_{\phi} \quad=\text { Formation damage coefficient } \\
& \phi_{o} \quad=\text { Initial Porosity, percent (\%) } \\
& \phi_{s} \quad=\text { Instantaneous porosity, percent (\%) } \\
& S_{w c} \quad=\text { Connate water saturation, percent }(\%) \\
& \mathrm{K}_{\mathrm{o}} \quad=\text { Initial Permeability, milli-Darcy }(\mathrm{mD}) \\
& \mathrm{K}_{\mathrm{s}} \quad=\text { Altered Permeability, milli-Darcy }(\mathrm{mD}) \\
& \mathrm{L}=\text { Horizontal Well Length, feet }(\mathrm{ft}) \\
& \mathrm{r}_{\mathrm{s}} \quad=\text { Radius of the altered zone, feet }(\mathrm{ft}) \\
& \mathrm{r}_{\mathrm{w}} \quad=\text { Wellbore radius, feet }(\mathrm{ft}) \\
& \mathrm{K}_{\mathrm{ro}} \quad=\text { Oil relative permeability, dimensionless } \\
& \mathrm{K}_{\mathrm{rw}}=\text { Water relative permeability, dimensionless } \\
& \mathrm{K}_{\mathrm{g}}=\text { Gas Relative Permeability, dimensionless } \\
& \Delta \mathrm{P} \quad=\text { Pressure Drop, } \mathrm{lb} / \mathrm{in}^{2}(\mathrm{psi}) \\
& \mu \quad=\text { Viscosity centi-poise (cp) } \\
& s_{\text {horizontal }}=\text { Horizontal Skin factor, dimensionless } \\
& \mathrm{J}=\text { Productivity Index, bbls/d/psi } \\
& \mathrm{M} \quad=\text { Mobility Ratio, dimensionless }
\end{aligned}
$$


a $\quad=$ Half of the major axis of drainage ellipse in a horizontal well, feet (ft)

$$
\beta=\text { Square root of permeability ratio, } \sqrt{k_{H} / k_{v}}
$$

\section{Subscripts}

$$
\begin{array}{ll}
\mathrm{H} & =\text { horizontal well } \\
V & =\text { Vertical well } \\
\mathrm{s} & =\text { skin } \\
\mathrm{eH} & =\text { drainage for horizontal well } \\
\mathrm{h} & =\text { horizontal } \\
\mathrm{o} & =\text { oil } \\
\mathrm{g} & =\text { gas } \\
\mathrm{w} & =\text { water }
\end{array}
$$

\section{ACKNOWLEDGEMENT}

The author gratefully acknowledge the effort of Esso Exploration \& Production Limited an ExxonMobil Subsidiary for providing fund to sponsor this project.

\section{SI Metric Conversion Factors}

$\begin{array}{lll}\text { bbl } & \times 1.589873 & \\ \text { psi } & \times 6.894757 & \text { E-01 }=m^{3} \\ \mathrm{ft} & \times 3.048^{*} & \text { E-00 }=\mathrm{Kpa} \\ \mathrm{cp} & \times 1.0^{*} & \mathrm{E}-01=\mathrm{m} \\ \mathrm{mD} & \times 9.869233 & \mathrm{E}-03=\mathrm{Pa} . \mathrm{S} \\ \left({ }^{\circ} \mathrm{F}-32\right) / 1.8 & \mathrm{E}-04=\mu \mathrm{m}^{2} \\ \end{array}$

\section{REFERENCES}

[1] P. G. Bedrikovetsky, P. M. Gladstone, Lope, Jr., F. F. Rosario, Silva, M. F., M. C. Bezerra and E. A. Lima, "Oilfield Scaling. Part II: Productivity Index Theory”, SPE Paper 81128, 2003 [Online] Available:www.spe.org/elibrarysearch [Assessed Feb.19, 2009].

[2] F. Civan, "Modelling Well Performance under Non Equilibrium Deposition Condition", SPE Paper 67234, 2001 [Online] Available:www.spe.org/elibrarysearch [Assessed Feb.19, 2009].

[3] A. S. Fadairo, O. Omole, and O. Falode, "Effect Of Oilfield Scale Deposition On Mobility Ratio", SPE Paper 114488, 2008 [Online] Available:www.spe.org/elibrarysearch [Assessed Feb.19, 2009].

[4] A. S. Fadairo, "Modeling Formation Damage Induced by Oilfield Scales". M.Sc thesis, University of Ibadan, Ibadan, Nigeria, 2004.

[5] O. J. Veter and V. Kandarpa, "Prediction of $\mathrm{CaCO}_{3}$ Scale Under Borehole Conditions", SPE Paper 8991, 1980 [Online] Available:www.spe.org/elibrarysearch [Assessed Feb.19, 2009].

[6] F. Frank, Chang and F. Civan, "Modeling of Formation Damage Due to Physical and Chemical Interaction between Fluid and Reservoir Rock", SPE Paper 22856, 1991 [Online] Available:www.spe.org/elibrarysearch [Assessed Feb.19, 2009].

[7] T. Haarberg, I. Selm, D. B. Granbakken, T. Østvold, P. Read and T. Schmidt, "Scale Formation in Reservoir and Production Equipment during Oil Recovery II, equilibrium Model", SPE $J$. Prod. Eng., Vol. 7, no. 1, 1998.

[8] H. Darcy, "Les Fontaines de la Ville de Dijon", Victor Dalmont, Paris, 1856 [Online] Available:www.spe.org/elibrarysearch [Assessed Feb.19, 2009].

[9] J. Moghadasi, A. Sharif, A. M. Kalantari and E. Motaie, "A New Model to Describe Particle Movement and Deposition in Porous Media" SPE Paper 99391, 2006 [Online] Available:www.spe.org/elibr arysearch [Assessed Feb.19, 2009].

[10] S. D. Joshi "Augmentation of Well Productivity with Slant and Horizontal Wells", J. Petrol. Technol., pp. 729-943, 1988 [Online] Available:www.spe.org/elibrarysearch [Assessed Feb.19, 2009].

[11] D. Joshi Sada, Horizontal Well Technology. Joshi Technologies International, Inc. Tulsa, Ok, USA, Penn Well Books: pp. 1-91, 1991.

[12] G. Atkinson, K. Raju and R. D. Howell, "The Thermodynamics of Scale Prediction", SPE Paper 21021, 1991 [Online] Available:www.spe.org/elibrarysearch [Assessed Feb. 19, 2009].

[13] G. I. Renard and J. M. Dupuy, "Influence of Formation Damage on the Flow Efficiency of Horizontal Wells", SPE Paper 19414, 1990 [Online] Available:www.spe.org/elibrarysearch [Assessed March $3,2009]$.

This is an open access article licensed under the terms of the Creative Commons Attribution Non-Commercial License (http://creativecommons.org/licenses/by$\mathrm{nc} / 3.0 /$ ) which permits unrestricted, non-commercial use, distribution and reproduction in any medium, provided the work is properly cited. 